\title{
EMPIRISMO E OBSERVAÇÃO: UMA PERSPECTIVA HISTÓRICA SOBRE A PRIMAZIA DA OBSERVABILIDADE NO EMPIRISMO CONSTRUTIVO DE VAN FRAASSEN
}

\author{
Alessio Gava ${ }^{1}$ \\ Universidade Estadual do Paraná (UNESPAR) \\ (iD) http://orcid.org/0000-0002-0426-8392
}

\section{RESUMO:}

A ênfase no papel da observação, uma das características salientes do empirismo, está reafirmada no empirismo construtivo de Bas van Fraassen através da primazia atribuída por esse à distinção entre observável e inobservável. Neste artigo será mostrado que, apesar de sua atualidade em filosofia da ciência, particularmente graças â enfase que van Fraassen the atribui, a questão da observação e da observabilidade na verdade é tão antiga quanto a própria filosofia e remete ao desejo, definitório do empirismo, de manter-se 'dentro dos limites'.

PALAVRAS-CHAVE: Empirismo; Empirismo construtivo; Observabilidade, Observação, Van Fraassen.

\section{EMPIRICISM AND OBSERVATION: A HISTORICAL PERSPECTIVE ON THE PRIMACY OF OBSERVABILITY IN VAN FRAASSEN'S CONSTRUCTIVE EMPIRICISM}

\footnotetext{
${ }^{1}$ Doutor em Filosofia pela Universidade Federal de Minas Gerais (UFMG), Minas Gerais Brasil. Professor da Universidade Estadual do Paraná (UNESPAR), Paraná - Brasil. E-mail: alessiogava@yahoo.it
} 


\section{ABSTRACT:}

The emphasis on the role of observation, one of the hallmarks of Empiricism, is reaffirmed by the primacy of the distinction between observable and unobservable in Bas van Fraassen's Constructive Empiricism. In this paper it will be showed that, despite being one the main topics of discussion in contemporary philosophy of science, particularly thanks to van Fraassen, the question of observation and observability is actually so old as philosophy itself and has to do with the willingness, that defines empiricism, to keep 'within the limits'.

KEYWORDS: Empiricism, Constructive Empiricism, Observability, Observation, Van Fraassen.

\section{Observação e observabilidade para os empiristas}

"Quando ouço a palavra filosofia tenho ganas de sacar o revólver", diz o detetive Pepe Carvalho, no romance $O$ labirinto grego, de Manuel Vázquez Montalbán. Mesmo sem chegar a esses extremos, a atividade filosófica sempre suscitou, desde seu surgimento na Grécia antiga, uma certa desconfiança, que às vezes até beira o escárnio, como na anedota de Tales e da escrava trácia. Manter o pé no chão, tanto literalmente quanto metaforicamente, em toda época foi considerada uma atitude sábia e a filosofia, mais do que qualquer outra atividade humana, é vista por muitos como uma disciplina que com facilidade transgride essa regra.

Até entre os próprios filósofos, 'devaneios' e excessivos afastamentos do bom senso frequentemente provocaram reações adversas e o nascimento de posições contrárias à 'mera especulação'. Foi assim que na Grécia de 2500 anos atrás, quando mais do que nunca a filosofia representou a summa de todos os saberes, medicina inclusa, o empirismo apareceu como atividade médica guiada pelos sentidos, em contraposição com a metodologia dos 'filósofos', cujo modus operandi consistia na postulação de hipóteses a partir das quais deduziam-se determinadas consequências.

Esse apelo à empeiria ( $\dot{\varepsilon} \mu \pi \varepsilon i p i ́ \alpha)$ mostra que o desejo de manter-se 'dentro dos limites' ( $\dot{\varepsilon} v-\pi \varepsilon i \tilde{\rho} \alpha \zeta$, hen - peiras), de confiar nas observações e na experiência, e o receio para com o dogmatismo e a teorização, são tão antigos quanto a própria filosofia e a acompanham como uma sorte de superego, pondo em guarda os filósofos contra os perigos de exceder-se.

O empirismo representa assim uma importante e antiga tradição, não identificável porém com uma posição específica e sim com uma série de posições que, particularmente a partir da 'profissionalização' da filosofia no

Empirismo e observação: uma perspectiva histórica sobre a primazia da observabilidade no empirismo construtivo de Van Fraassen - Alessio Gava 
século XIX, foram classificadas como empiristas. O empirismo foi então definido como a teoria segundo a qual todo conhecimento deriva da experiência, remetendo particularmente ao célebre Ensaio sobre o Entendimento Humano de John Locke (1689) (cf. VAN FRAASSEN 2002, 3435, entre outros).

Jennifer Nagel afirma peremptoriamente que, ainda hoje, "o empirismo é a posição segundo a qual a experiência é a única fonte de garantia para afirmações acerca do mundo" (NAGEL 2006, 235, tradução nossa), acrescentando pouco em seguida que foi a versão do empirismo apresentada por Locke em 1689 que ainda inspira os adeptos contemporâneos dessa posição. ${ }^{2}$

Nas primeiras décadas do século XX, o empirismo casou-se com o positivismo, dando origem ao positivismo lógico, a partir dos trabalhos do Círculo de Viena e da Sociedade de Filosofia Empírica de Berlim, nos anos 20. Inspirados pelos avanços no campo da lógica e pelas revoluções que estavam acontecendo na física, e não só, e, em filosofia, pelo trabalho de Wittgenstein e pelo empirismo eliminativista de Ernst Mach, os adeptos dos dois grupos utilizaram os métodos lógico-matemáticos para defender muitos dos principais princípios positivistas. Entre eles, a recusa da metafísica, o reconhecimento da ciência como única forma legítima de conhecimento e a ideia que o objetivo da filosofia é elucidar a estrutura ou a lógica da ciência (cf. NAGEL 2006 e LADYMAN 2007, entre (muitos) outros).

Como escreve Urbano Zilles, "entre os membros havia uma orientação fundamental comum: a cientificidade da filosofia" (2006, 205). Para eles, a questão da significação era central, mas o significado de uma palavra deveria repousar sobre algo que se pode mostrar e não pode ser caracterizado (somente) a partir de outras palavras. Por isso, diferentemente das versões mais antigas do empirismo, "colocam todo o peso na elaboração lógica dos dados empíricos, ou seja, na linguagem" (ibid.).

Depois da caracterização de Hume, segundo a qual as ideias são construídas a partir dos dados sensoriais, os empiristas lógicos do século XX, interessados em fornecer uma construção lógica e não psicológica das ideias, preocuparam-se em falar de observação, e não de impressões. Mas a perspectiva linguística que adotaram ${ }^{3}$ os levou a falar em termos observacionais, mais do que em observação (cf. SHAPERE 2006).

\footnotetext{
${ }^{2}$ A opinião de Nagel é largamente aceita. Um artigo de Peter Baumann recém publicado, por exemplo, se abre com as seguintes palavras: "O empirismo pode ser sumariamente (very roughly) caracterizado como a visão segundo a qual nosso conhecimento do mundo é baseado na experiência sensível" (2011, 27, tradução nossa).

3 "Impressionados com as realizações da lógica e dos estudos fundacionais na matemática no início do século $\mathrm{XX}$, os filósofos começaram a pensar as teorias científicas em um viés ling[u]ístico. Para apresentar uma teoria, especificava-se uma linguagem exata, algum conjunto
}

Empirismo e observação: uma perspectiva histórica sobre a primazia da observabilidade no empirismo construtivo de Van Fraassen - Alessio Gava 
Segundo a chamada abordagem sintática, ${ }^{4}$ própria do positivismo lógico, uma teoria consistiria em um conjunto de postulados e teoremas, formulados em uma linguagem específica. $\mathrm{O}$ vocabulário dessa linguagem é dividido em duas classes, a classe dos termos (ou das sentenças) observacionais e aquela dos termos teóricos (ou das sentenças teóricas). Os termos do vocabulário observacional $V_{O}$ designariam propriedades observáveis de objetos ou eventos ou relações observáveis entre eles. Já $V_{T}$, o vocabulário teórico, conteria termos que podem fazer referência a objetos e eventos inobserváveis ou aspectos deles. 5

A preocupação empirista com a experiência sensível assumiu a forma de uma reformulação da linguagem da ciência, utilizando a lógica formal como chave que permitiria a construção de uma linguagem científica perfeita, livre de conceitos sem sentido, como 'ser' ou 'Deus', cujas sentenças deveriam poder ser traduzidas, sem resíduos, em proposições atômicas empíricas, as Protokollsätzen.

Com isso, a questão da observabilidade ganhou uma posição de relevo na filosofia da ciência, mas, na abordagem neopositivista, tratava-se de uma questão linguística e a determinação de quais seriam os fenômenos observáveis não fez parte da agenda empirista da época. ${ }^{6}$

É opinião corrente que o positivismo lógico, porém, "teve um fracasso bastante espetacular" (VAN FRAASSEN 2007, 22) e, de fato, parece que o projeto de Carnap, Hempel e dos outros herdeiros dos Círculos de Viena e Berlim foi abandonado há quatro ou cinco décadas atrás. ${ }^{7}$ Menosprezar a

de axiomas e um dicionário parcial, que relacionava o dialeto teórico com os fenômenos observáveis que são relatados" (VAN FRAASSEN [1980] 2007, 121).

${ }_{5}^{4}$ Locução utilizada por Carnap em 1934, quando escreveu A sintaxe lógica da linguagem.

5 'Todos concordariam que termos para propriedades, como 'azul', 'duro', 'frio', e termos para relações, como 'mais quente que', 'mais pesado que', 'mais brilhante que', são observacionais, enquanto 'carga elétrica', 'próton', 'campo eletromagnético' são termos teóricos, que se referem a entidades que não podem ser observadas de uma maneira simples e direta" (CARNAP 1974, 258, tradução nossa).

${ }^{6}$ Carnap até admitiu a possibilidade de traçar a linha de demarcação entre observáveis e inobserváveis de modo diferente dependendo do contexto e das exigências. Importante para ele, ao que parece, era que, de qualquer maneira, a linha existe (cf. CARNAP 1974, 225-226). Por sua vez, Hempel afirmou que, para o estudo da estrutura das teorias, não importa saber onde cai tal linha divisória (cf. HEMPEL 1976, 105).

${ }^{7}$ Um pouco diferente é a posição de Wesley Salmon, segundo o qual a posição do Círculo de Viena é conhecida como positivismo lógico, enquanto o empirismo lógico surgiu em Berlim e 'absorveu' o positivismo na segunda metade do século XX. Salmon, contrariamente à opinião corrente, sustenta que o positivismo lógico morreu, mas o empirismo lógico continua vivo e forte na filosofia da ciência (cf. SALMON 1999). Mas segundo Philipp Frank, um dos membros fundadores do Círculo de Viena, empirismo lógico e positivismo lógico são dois 
questão da observabilidade, quando a "visão recebida" ${ }^{8}$ tinha como fundamento uma distinção entre vocabulário observacional e vocabulário teórico, constituiu, evidentemente, um 'calcanhar de Aquiles' para o empirismo lógico. A suposta impossibilidade de traçar uma linha divisória nítida, ou de traçar uma separação tout court, foi um argumento utilizado por muitos autores para derrubar a tese da intepretação parcial. "As dificuldades insuperáveis que afetam a tentativa instrumentalista de traçar uma nítida distinção entre vocabulários observacional e teórico constituiu o núcleo da virada realista contra uma filosofia da ciência instrumentalista”, escreveu Michael Luntley em 1982 (p. 245, tradução nossa).

$\mathrm{O}$ abandono do projeto neopositivista determinou um breve período de aparente hegemonia, no panorama da filosofia da ciência, do chamado realismo científico, por volta dos anos $70 .{ }^{10}$ Mas durou pouco, apesar de, na época, poder-se ler até que "o caixão do empirismo está devidamente lacrado" (VAN FRAASSEN 2007, 21). A publicação, em 1980, de A Imagem Científica, por parte do filósofo holandês Bas van Fraassen, constituiu a 'volta por cima' do antirrealismo. ${ }^{11} \mathrm{O}$ livro teve uma repercussão excepcional e projetou van Fraassen como figura de destaque no panorama atual da filosofia da ciência. Entre os muitos que lhe reconhecem, ainda hoje, o papel de principal referência para o empirismo contemporâneo, citamos novamente Jennifer Nagel: "A versão do empirismo que constitui a contribuição mais influente para a epistemologia tradicional desde o desmoronamento do positivismo, foi proposta por Bas van Fraassen, em favor da visão da ciência que ele chama de "empirismo construtivo"' (2006, 240, tradução nossa).

rótulos utilizados indiferentemente para referir-se ao movimento que se originou a partir dos trabalhos do Círculo (cf. FRANK 1950, cap. 1).

${ }^{8}$ A maneira dos herdeiros dos Círculos de Viena e Berlim de conceber as teorias científicas passou a ser conhecida, na literatura, como visão ortodoxa ou visão recebida.

9 Trata-se da tese, de Carnap, segundo a qual é expressamente proibido que um termo do vocabulário teórico tenha uma interpretação observacional direta. A única interpretação observacional de um termo teórico é aquela dada indireta e parcialmente pelas chamadas regras de correspondência. Tal tese está intimamente ligada à distinção observacional/teórico.

${ }^{10}$ Inúmeros textos relatam que o realismo científico dominou o panorama da filosofia da ciência nos anos 70, talvez desconsiderando o trabalho de autores importantes como Kuhn e Laudan, que porém, de fato, quase nunca encontramos citados. A única exceção é representada pelo artigo "Van Fraassen's unappreciated Realism", no qual Ernan McMullin escreve que "a resurreição do antirrealismo na filosofia da ciência nos anos 60 foi em grande parte causada pelos desafios propostos em A estrutura das revoluções científicas de Kuhn (1962)" (MCMULLIN 2003, 463, tradução nossa) e, em seguida, cita também Laudan.

${ }^{11}$ Van Fraassen afirma claramente em A Imagem Científica que sua posição filosófica é antirrealista (cf. p. 31) e parece defender em vários textos que sua tese antirrealista científica é uma consequência natural de ter endossado o empirismo (cf. CHIBENI 1997, 258-260).

Empirismo e observação: uma perspectiva histórica sobre a primazia da observabilidade no empirismo construtivo de Van Fraassen - Alessio Gava 
Segundo a filósofa canadense, van Fraassen consegue, utilizando-se de uma distinção entre crença e aceitação, ${ }^{12}$ defender uma posição empirista em relação à ciência sem requerer uma reformulação, de estampa positivista, da linguagem das teorias. Ele concorda com os neopositivistas no reconhecimento da importância, do ponto de vista epistêmico, da demarcação entre aquilo que é observável e aquilo que não é, mas não tenta encontrar uma maneira sintática de traçar a linha, pois isso só poderia ser levado a cabo no plano empírico, das entidades e dos eventos físicos. Não é possível, diz van Fraassen concedendo um ponto aos realistas, subdividir a linguagem da ciência em um vocabulário observacional e um vocabulário teórico. Toda linguagem é, de fato, admite, 'impregnada de teoria'. A distinção, portanto, deve ser procurada mais em baixo, em nossa interação direta com o mundo, no plano dos fenômenos.

Talvez por essa centralidade reconhecida à questão da observação e da observabilidade nas últimas décadas, e van Fraassen certamente tem um papel importante nisso, a ênfase empirista no papel da experiência é vista atualmente como fundamentação do conhecimento na observação. Um filósofo da ciência conhecido e respeitado como Dudley Shapere, por exemplo, escreveu em 2006 que "o empirismo é a doutrina segundo a qual todas nossas ideias são baseadas na observação" (p. 523, tradução nossa). Pode, essa afirmação de Shapere, servir como definição?

Tradicionalmente, uma caracterização do empirismo encontra-se associada à disputa com o racionalismo sobre o fundamento do conhecimento. Contra os racionalistas, que afirmam que conceitos e conhecimento podem ser adquiridos de várias maneiras, os empiristas sustentam que a experiência sensível é a única fonte deles. Mas se essa era a situação no tempo de Descartes, Locke e Hume, ao que tudo indica hoje em dia não há mais defensores de uma posição racionalista, na cena filosófica. ${ }^{13} \mathrm{O}$ debate agora

\footnotetext{
${ }^{12}$ É possível, segundo van Fraassen, que endossa uma posição epistemológica conhecida como voluntarismo, distinguir entre crença, limitada à parte observacional da teoria - a chamada subestrutura empírica -, e aceitação, atitude que deve ser reservada para tudo aquilo que de inobservável é postulado/introduzido pela teoria. Por trás disso está um modelo de racionalidade permissivo (típico da tradição anglo-saxã) e não normativo (característico da tradição continental), endossado pelo filósofo holandês. Segundo a 'epistemologia voluntarista' de van Fraassen, pois, como bem explica Dicken (cf. 2010, 23), a racionalidade deve ser considerada mais uma questão de permissão do que de obrigação; com isso, pode-se legitimamente acreditar em tudo aquilo que não somos racionalmente forçados a não acreditar. Existe um debate aberto, muito recente, sobre o voluntarismo de van Fraassen e sobre os problemas que essa posição poderia acarretar para a visão da ciência e a proposta empirista do filósofo holandês. Veja-se, por exemplo, Steup (2011), Baumann (2011) - onde o voluntarismo de van Fraassen é explicado de forma sintética, mas muito clara - e Dicken (2010), entre outros. 13 “ $\mathrm{O}$ interesse dos epistemólogos que se ocupam das ciências naturais parece ter-se inclinado irreversivelmente para o empirismo depois que teorias consideradas paradigmas de
}

Empirismo e observação: uma perspectiva histórica sobre a primazia da observabilidade no empirismo construtivo de Van Fraassen - Alessio Gava 
parece ter se deslocado do terreno (puramente) epistemológico para a filosofia da ciência e ter assumido a forma de uma disputa entre realismo e antirrealismo, para usar a terminologia corrente. ${ }^{14}$

Nessa perspectiva, os defensores do empirismo tradicional seriam os antirrealistas $^{15}$ e van Fraassen, como foi dito, uma de suas figuras de destaque. Contudo, o realismo científico dificilmente pode ser visto como um apêndice do racionalismo, ou sua versão contemporânea, apesar de os realistas admitirem a legitimidade de inferências na construção do conhecimento. Parece mais uma disputa interna ao empirismo, uma vez que o racionalismo desapareceu, entre quem propugna uma versão 'ortodoxa' e quem defende uma leitura mais 'liberal' do que significa ser empirista. ${ }^{16}$

Seja como for, o que significa ser empirista é atualmente objeto de debate e o próprio van Fraassen abandonou a ideia segundo a qual o empirismo é uma posição filosófica que se reconhece em um princípio-base - que seria, no caso, aquele de que a experiência é a única legítima fonte de informação acerca do mundo - em favor de uma sua caracterização como conjunto de atitudes e crenças a serem identificadas como traços comuns das várias posições que, historicamente, foram definidas empiristas. O empirismo é uma stance, diz agora o filósofo holandês, que prefere não falar mais em experiência na caracterização dessa vertente filosófica. ${ }^{17}$

conhecimento a priori, como a geometria euclidiana e a mecânica clássica, cederam lugar a teorias incompatíveis, no processo evolutivo da ciência" (CHIBENI 1997, 257).

${ }^{14}$ Segundo Silvio Chibeni, realismo e antirrealismo são duas posições epistemológicas cuja distinção é ortogonal àquela entre empirismo e racionalismo. A primeira distinção tem a ver com a questão da extensão ou dos limites do conhecimento, já a segunda se dirige à questão dos seus fundamentos, ou justificação. O professor da Unicamp acusa van Fraassen de não traçar uma distinção explícita entre empirismo e antirrealismo e acrescenta que, infelizmente, "a literatura recente mostra acentuada tendência para confundir essas duas doutrinas" (CHIBENI 1997, 260).

${ }^{15}$ Segundo Elliott Sober, trata-se de um tipo diferente de empirismo. Haveria, isto é, um empirismo que contrasta com o racionalismo e um empirismo que contrasta com o realismo científico (cf. 2008, 129). Veja-se, a esse respeito, a nota anterior.

${ }^{16}$ Cf. Ellis 1985, p. 48, e Alspector-Kelly 2004, por exemplo. Segundo Alspector-Kelly, todavia, uma implícita acusação de racionalismo está subjacente à crítica de van Fraassen ao realismo científico (cf. 2004, 336, nota 14). Entretanto, ainda em 1944, Roy Wood Sellars escrevia que "o realista sempre considerou-se um empirista. A recusa empirista do racionalismo intuicionista é uma parte aceita de sua tradição" (p. 535, tradução nossa).

${ }^{17}$ Há vários textos que mostram a mudança de postura de van Fraassen com relação ao que significa ser empirista. Dois livros importantes a esse respeito são The Empirical Stance (2002) e Images of Empiricism (2007). O artigo "The Empiricist Conception of Experience" (2000), de Jennifer Nagel, mostra como a caracterização de experiência por parte do filósofo holandês fosse de fato problemática.

Empirismo e observação: uma perspectiva histórica sobre a primazia da observabilidade no empirismo construtivo de Van Fraassen - Alessio Gava 
A cada século a filosofia se encontra na necessidade de reinterpretar a si mesma e a tradição empirista, como toda tradição, não pode manter-se viva a não ser que se renove, escreve van Fraassen na introdução de The Empirical Stance (2002). Contudo, há um 'patrimônio genético comum' que identifica todo empirista e que deve permanecer intacto, como a aversão à metafísica e a rejeição de pedidos de explicação em certos pontos cruciais, além da consideração da ciência como paradigma de investigação racional. Em razão disso, o apelo à empeiria para ancorar o conhecimento pode ter mudado na forma, mas não na substância, e a ênfase no papel da experiência refinou-se e objetivou-se no século XX, reapresentando-se como centralidade do ato de observação e da questão da observabilidade. Não que esses conceitos sejam menos problemáticos, como já Hume e Locke tinham claro (cf. AUNE 2008, 95-96), mas deveria tratar-se de algo mais objetivo e 'científico' do que o conceito de experiência, o qual poderia até induzir a pensar que a psicologia possa ter algo importante a dizer a esse respeito. Mas nesse debate não há mais espaço para 'fantasmas filosóficos' como os dados sensoriais, segundo van Fraassen, contra os quais, em A Imagem Científica, declara abertamente sua recusa (cf. 2007, 135).

Há todavia uma crítica importante de Arthur Fine, de 1986, a qual parece indicar que, mutatis mutandis, a situação para o empirismo não mudou muito. O filósofo norte-americano sustenta que o esforço empirista de criar um estatuto epistêmico especial para afirmações acerca dos observáveis só pode ser baseado em um comprometimento a priori que não combina com a orientação básica do empirismo. As observações, por si só, não levam a ter uma atitude epistêmica particular com relação à própria observação (cf. Fine 1986). Assim, afirma Jennifer Nagel, o empirismo seria uma teoria acerca de quais afirmações são garantidas no interior da ciência; a questão, separada, de quais sentenças são justificadas na epistemologia estaria além do escopo do próprio empirismo (cf. NAGEL 2006, 243).

Um certo paralelo pode ser encontrado na obra de van Fraassen, que em A Imagem Científica, provavelmente ainda seu texto mais famoso, tentou definir o que é a ciência empírica na perspectiva de um (aspirante) empirista, sem que isso respondesse à pergunta sobre o que significa ser empirista. Essa resposta ele tentou dar no livro The Empirical Stance de 2002, mas a caracterização do empirismo, como foi dito, é um tema ainda objeto de debate. ${ }^{18}$ Contudo, o papel da observação continua constituindo uma referência crucial para o empirismo, mesmo em uma época em que esse parece sofrer de uma 'crise de identidade'.

18 Veja-se, por exemplo, o recente Images of Empiricism (2007), que reune textos de van Fraassen e outros filósofos.

Empirismo e observação: uma perspectiva histórica sobre a primazia da observabilidade no empirismo construtivo de Van Fraassen - Alessio Gava 
É esse o caso, certamente, para o empirismo construtivo, a visão acerca da ciência e de seus objetivos que van Fraassen expôs em A Imagem Científica. Conforme foi antecipado, e será ilustrado na última seção, essa vertente antirrealista está fundamentada na possibilidade de distinguir entre crença e aceitação e tal distinção espelha (e repousa sobre) uma demarcação, no plano empírico, entre observáveis e inobserváveis. Sem tal linha divisória, o edifício filosófico construído por van Fraassen desmoronaria.

\section{Observação e observabilidade para os realistas}

O ideal da ciência como padrão de indagação racional e a própria ciência como objeto de análise e pesquisa tornam inevitavelmente central a questão da observabilidade para uma posição empirista em filosofia da ciência. Mas até para posições que se definem realistas, já que, pode-se afirmar, toda teoria científica é construída a partir de observações, não necessariamente pelo fato de as teorias serem o produto de uma atividade indutiva, o que pode ser discutível, mas porque certamente um de seus principais objetivos é dar conta das 'aparências' sensíveis.

Como nos lembra Jesús Mosterín, um dos principais filósofos espanhois da atualidade, nas ciências empíricas, observação e experimentos desenvolvem o papel de interface entre as representações simbólicas, com as quais as teorias são formuladas e formalizadas, e as apresentações da realidade exterior (cf. MOSTERÍN 1998, 1). O papel da observação é, portanto, absolutamente central na atividade cientifica e é evidente que na filosofia da ciência constitui um assunto de discussão crucial. De fato, a questão da observabilidade, mesmo sob formas diferentes, perpassa boa parte da filosofia da ciência do século XX e deste início do século XXI e representa um dos principais temas de debate no confronto entre realismo e antirrealismo.

No caso do realismo científico, todavia, o interesse pela questão da observabilidade parece mais um reflexo da ênfase dada ao tema pelos empiristas do que um efetivo reconhecimento da sua importância. Sem negar o papel do ato de observação, os realistas consideram que a adequação empírica de uma teoria - sua capacidade de 'salvar os fenômenos' - é só uma das virtudes que nos permitem julgar se estamos no caminho do objetivo da ciência, aquele, segundo a reconstrução de van Fraassen (cf. 2007, p. 27), de nos fornecer teorias verdadeiras. ${ }^{19^{3}}$

\footnotetext{
${ }^{19}$ Apesar de a caracterização do realismo científico por parte de van Fraassen encontrar respaldo nos enunciados de realistas reconhecidos como Sellars, Putnam e Boyd, alguns autores acusam o filósofo holandês de ter definido essa posição de maneira demasiado forte, o que facilitaria a sua 'cruzada antirrealista' (cf. SICHA 1992, 522-523).
}

Empirismo e observação: uma perspectiva histórica sobre a primazia da observabilidade no empirismo construtivo de Van Fraassen - Alessio Gava 
Apesar de se haver várias correntes realistas, autores como Richard Boyd e Howard Sankey defendem - sub specie o propósito de se fazer ciência que o realismo científico constitui uma doutrina filosófica propriamente dita, a ponto de proporem uma formulação do mesmo. Segundo Sankey, "o realismo científico é a visão segundo a qual o objetivo da ciência é o conhecimento da verdade acerca de aspectos observáveis e inobserváveis de uma realidade objetiva e independente da mente" (2001, 35, tradução nossa). Similarmente, Boyd escreve:

\begin{abstract}
Os realistas científicos mantêm que o produto característico de uma pesquisa científica de sucesso é o conhecimento de fenômenos amplamente independentes de teorias e que tal conhecimento é possível (real, de fato) até naqueles casos em que os fenômenos relevantes não são observáveis (2002, tradução nossa).
\end{abstract}

Mas se, ao se constituirem como resposta ao 'desafio empirista', acerca da possibilidade de conhecermos entidades 'teoricas' inobserváveis, essas definições remetem à questão da observabilidade, ganha força a impressão de que o realismo tende a apresentar-se como um 'anti-antirrealismo', mais direcionado a refutar a posição empirista do que preocupado em propor uma vertente diferente e independente. $\mathrm{Na}$ agenda realista, de fato, observação e observabilidade adquirem importância somente por serem assuntos cruciais para uma posição empirista em filosofia da ciência. Os realistas, isto é, dedicaram-se com profusão à questão, mas, na maioria das vezes, utilizando-se da suposta impossibilidade de levar a cabo a tarefa de distinguir entre observáveis e inobserváveis para atacar o antirrealismo em seus alicerces.

Com efeito, examinando os textos dos autores realistas, adquire-se a impressão que, na linha argumentativa geral, a estratégia seja quase sempre aquela de tentar derrubar o empirismo. Os argumentos realistas parecem normalmente mais direcionados a isso do que a propor uma posição diferente e independente, a começar pelo clássico artigo de Grover Maxwell, "The Ontological Status of Theoretical Entities" (1962). Como justamente releva van Fraassen, o texto de Maxwell, além der constituir o locus classicus da nova argumentação realista de que a distinção teoria/observação não pode ser feita, é evidentemente uma oposição direta ao seminal artigo de Carnap "The methodological character of theoretical concepts" (1956) tanto no título quanto no tema (cf. VAN FRAASSEN 2007, 36).

$\mathrm{O}$ artigo de Maxwell, isto é, representa uma referência para o realismo científico não somente por ser um dos textos que determinaram o surgimento dessa corrente filosófica, mas também por indicar a estratégia a ser seguida pelos autores que, posteriormente, reconheceram-se no rótulo de 'realistas', fato

Empirismo e observação: uma perspectiva histórica sobre a primazia da observabilidade no empirismo construtivo de Van Fraassen - Alessio Gava 
que justifica, poder-se-ia dizer, uma caracterização do realismo como vertente 'anti-antirrealista'. ${ }^{20}$

O resultado disso é que, após décadas de posições dominantes, a filosofia da ciência dos últimos trinta anos se distingue por um amplo debate no qual ideias diferentes se confrontam e se refinam, no mais puro espírito dialógico que constitui a própria essência da atividade filosófica. Um dos assuntos sobre o qual realistas e antirrealistas mais disputam é, ficou claro, a questão da observabilidade, como demonstram a vasta literatura a respeito e o fato de artigos sobre o tema continuarem sendo publicados.

Isso mostra também que, evidentemente, o assunto não se esgotou. E se a definição de observável, ao que parece, não ocupa mais o centro do debate, entender o que significa observar - talvez chegar a uma teoria da observação satisfatória - parece constituir o principal frente da atualidade.

Mas por quê, para o empirismo construtivo, e para o empirismo em geral, a observação é tão importante? O que tem, de tão bom, nesse tipo de interação entre o sujeito e o mundo? Van Fraassen defende a tese antirrealista segundo a qual o conhecimento se limita estritamente àquilo que é diretamente observável e isso é, segundo ele, uma consequência direta do endossar o empirismo (cf. CHIBENI 1997, 259). Por trás há uma identificação, tipicamente empirista, entre observabilidade e inteligibilidade. ${ }^{21}$ A fonte e o fundamento do conhecimento, a observabilidade, isto é, coincidiria com, ou determinaria, extensão e alcance do conhecimento, a inteligibilidade. $\mathrm{O}$ empirismo construtivo, assim, se apresenta como uma tese epistemológica onde antirrealismo e empirismo, apesar de a rigor serem teses epistemológicas sobre questões diferentes, se sobrepõem e se confundem, o que explica o fato que na literatura recente, e no uso de van Fraassen, os dois termos são utilizados como sinônimos.

\section{0 empirismo construtivo}

Em 1980, em uma época em que declarar-se empiristas em filosofia da ciência parecia querer defender uma posição derrotada e ultrapassada, o holandês Bas van Fraassen publicou um livro destinado a reverter essa situação e que ainda hoje constitui uma importante referência no debate acerca do

\footnotetext{
${ }^{20}$ Vale lembrar que, no mesmo ano do artigo de Maxwell, foi publicado "What theories are not", de Hilary Putnam. Esse também é um dos textos que marcaram o surgimento do realismo científico e também nesse caso o título é uma oposição direta à 'visão recebida'.

${ }^{21}$ No núcleo da epistemologia instrumentalista das primeiras décadas do século XX, por exemplo, segundo Michael Luntley, encontrava-se uma identificação entre inteligibilidade e observabilidade (cf. 1982, 248).
}

Empirismo e observação: uma perspectiva histórica sobre a primazia da observabilidade no empirismo construtivo de Van Fraassen - Alessio Gava 
empreendimento científico. The Scientific Image foi traduzido e editado em vários países do mundo e no Brasil, com o título de A Imagem Científica, publicado em 2007. Nele, van Fraassen propõe uma alternativa 'construtiva',22 ao realismo científico, a qual, apesar de ser uma posição empirista, deveria distanciar-se em igual medida tanto do realismo quanto do neopositivismo, vertente de fato derrotada e ultrapassada.

Para tanto, o filósofo holandês repudia a chamada abordagem sintática e propõe uma nova maneira de considerar as teorias científicas. A visão neopositivista da estrutura da ciência, orientada linguisticamente, na qual as teorias são identificadas como conjuntos de teoremas redigidos em uma linguagem específica, é substituída por van Fraassen por uma abordagem semântica, ${ }^{23}$ na qual as teorias são concebidas como um conjunto de modelos. ${ }^{24}$ Um modelo de uma teoria é, segundo essa perspectiva, qualquer estrutura (normalmente matemática) que satisfaça os axiomas da teoria, na qual todos os parâmetros relevantes possuem valores determinados. ${ }^{25}$

Mesmo essa nova imagem das teorias, todavia, é compatível tanto com uma abordagem antirrealista quanto com uma abordagem realista. Por isso, um papel-chave é desempenhado pelo conceito de adequação empírica: uma teoria científica é dita empiricamente adequada se todos os resultados de experimentos e observações (as aparências) são isomorfos à parte observacional (subestrutura empírica) de pelo menos um modelo dessa (cf. VAN FRAASSEN 2007, 267). ${ }^{26}$ Esse conceito estaria ligado à própria meta do empreendimento científico, conforme se lê em A Imagem Científica:

${ }^{22} \mathrm{O}$ empirismo proposto por van Fraassen ganha o adjetivo construtivo para indicar que "a atividade científica é uma atividade de construção, em vez de descoberta: construção de modelos que devem ser adequados aos fenômenos, e não descoberta da verdade sobre o que é inobservável" (2007, 22).

23 "A concepção semântica das teorias deriva de uma aplicação das modernas teorias semânticas em lógica à filosofia da ciência” (SICHA 1992, 520, tradução nossa).

${ }^{24}$ Ao introduzir um texto de 1970 de Herbert Feigl, um dos principais exponentes do empirismo lógico, Osvaldo Pessoa explica brevemente a essência da diferença entre as duas perspectivas: "A diferença principal entre essas duas abordagens é que os empiristas lógicos tendiam a identificar uma teoria científica com os próprios postulados e teoremas expressos em linguagem lógica, ao passo que a visão semântica identifica uma teoria científica com os modelos (em geral expressos na teoria dos conjuntos) que satisfazem o formalismo lógico. Uma vantagem da visão semântica é que se pode exprimir facilmente o fato de que uma mesma teoria científica pode ser formulada a partir de diferentes axiomatizações" (PESSOA 2004, 261).

${ }^{25}$ Mas é bom ter em mente que "modelo é uma metáfora (...). Poderíamos ter usado a palavra mapa, e feito muito bem dos mapas a base de nossa metáfora" (VAN FRAASSEN 1992, 8, tradução nossa).

${ }^{26}$ Em outra passagem de A Imagem Científica se lê: "Uma teoria é empiricamente adequada exatamente se é verdadeiro o que ela diz sobre as coisas observáveis e eventos no mundo -

Empirismo e observação: uma perspectiva histórica sobre a primazia da observabilidade no empirismo construtivo de Van Fraassen - Alessio Gava 
a ciência visa dar-nos teorias que sejam empiricamente adequadas; e a aceitação de uma teoria envolve, como crença, apenas aquela de que ela é empiricamente adequada. Esse é o enunciado da posição anti[r]realista que defendo; vou denominá-la empirismo construtivo (VAN FRAASSEN 2007, 33-34, ênfase no original).

Tendo em vista o objetivo da ciência, van Fraassen substitui assim o 'tradicional' conceito realista de verdade pelo de adequação empírica, sendo esta última a principal virtude que uma teoria deve apresentar. "Desse modo, vou argumentar em favor de uma posição empirista, e contra o realismo científico", escreveu (VAN FRAASSEN 2007, 21).

Ora, é evidente que os dois conceitos têm uma relação bastante estreita e falar de substituição requer uma qualificação, para que não se pense que a adequação empírica seja algo substancialmente diferente do conceito de verdade (como correspondência). Como bem escreve Chakravartty, diversamente, "o empirismo construtivo é a visão segundo a qual o objetivo da ciência é a verdade acerca dos observáveis e não a verdade de maneira mais geral" (CHAKRAVARTTY 2007, 12, tradução nossa). Aquilo que van Fraassen faz, dito de outra maneira, é restringir o domínio de aplicação da noção realista de verdade, de todas as entidades postuladas por uma teoria científica para aquelas observáveis apenas, mas a busca da verdade (mesmo que em sua variante 'parcial', restrita aos fenômenos observáveis, a que van Fraassen chama de 'adequação empírica') continua sendo o propósito da atividade científica, inclusive na reconstrução do filósofo holandês.

Com efeito, pode até acontecer de os conceitos de verdade e de adequação empírica coincidirem, quando uma teoria ou uma hipótese limitamse a descrever unicamente fenômenos observáveis, como é atestado pelo próprio van Fraassen em A Imagem Científica: "Quando a hipótese é apenas sobre o que é observável, os dois procedimentos [formar a crença de que a hipótese é verdadeira ou formar a crença de que a hipótese é empiricamente adequada] resultam no mesmo" (VAN FRAASSEN 2007, 134). O antirrealismo do filósofo holandês, em suma, 'somente' representa uma tomada de posição contra as conclusões mais 'radicais' do realismo científico, segundo as quais deveríamos tomar como verdadeira (tout court) uma teoria científica aceita, até em sua descrição de uma hipotética realidade inobservável por trás dos fenômenos aos quais temos acesso direto, e nada tem a ver com a eventual negação da realidade do mundo material. Em outras palavras, é um

exatamente, se ela 'salva os fenômenos'. Um pouco mais precisamente: tal teoria possui pelo menos um modelo tal que todos os fenômenos reais a ele se ajustam” $(2007,34)$.

Empirismo e observação: uma perspectiva histórica sobre a primazia da observabilidade no empirismo construtivo de Van Fraassen - Alessio Gava 
antirrealismo 'seletivo', somente acerca dos inobserváveis. ${ }^{27}$ Nessa perspectiva, ser antirrealista apenas significa não aceitar a ideia de que as teorias científicas descrevam corretamente todos os aspectos desse mundo.

Isso comporta, também, não julgar o realismo como única doutrina que conseguiria dar conta do empreendimento científico (como parecia ser o caso nos anos em que A Imagem Científica foi publicado), mas disso não se segue que as teorias científicas necessitariam ser interpretadas para serem boas. Se todas as teorias científicas fossem apenas acerca de observáveis, podemos depreender, realismo científico e empirismo construtivo coincidiriam. Tanto que em seu último livro, Scientific Representation, van Fraassen escreveu: "Eu tento ser um empirista e por como eu entendo essa tradição (...) ela envolve um realismo do senso comum no qual a referência aos fenômenos observáveis não é problemática: pedras, mares, estrelas, pessoas, bicicletas..." (VAN FRAASSEN 2008, 3, tradução nossa).

O tipo de antirrealismo que o filósofo holandês endossa marca assim, ao mesmo tempo, um afastamento das posições neopositivistas, caracterizadas por uma interpretação não-literal da linguagem da ciência. Van Fraassen defende que essa deve ser, ao contrário, literalmente interpretada, assim como fazem os realistas. Contudo, considerar a linguagem científica de maneira diferente daquela do antirrealismo das primeiras décadas do século XX não implica em uma adesão ao realismo, porque as teorias científicas não precisam ser verdadeiras para serem boas, a não ser no que diz respeito aos fenômenos observáveis (cf. 2007, 31-33). "Salvar os fenômenos" é o lema do empirismo construtivo.

É possível, pois, segundo o filósofo holandês, distinguir entre crença, limitada à parte observacional da teoria, e aceitação, atitude que deve ser reservada para tudo aquilo que de inobservável é postulado/introduzido pela teoria, como foi dito anteriormente. Nesse sentido, a parte não empiricamente atestável de uma teoria deve ser tomada como útil instrumento que é parte de uma teoria empiricamente adequada e nada mais. Com relação a essa se suspende o juízo, agnosticamente.

Van Fraassen expressou de maneira bastante radical essa diferente atitude para com as diversas partes de uma teoria em um artigo de 2005, "The day of the dolphins", no qual escreveu que "o que as ciências falam acerca das partes observáveis do mundo é verdadeiro, o resto não interessa” (p. 112, tradução nossa). Discriminar a parte observável do mundo daquela nãoobservável é portanto crucial para o empirismo construtivo. No prefácio à

27 "A essência da controvérsia entre realistas e antirrealistas concerne à possibilidade de se haver conhecimento do inobservável e essa possibilidade é contrastada de modo mais forte por várias formas de empirismo" (CHAKRAVARTTY 2007, xiii, tradução nossa).

Empirismo e observação: uma perspectiva histórica sobre a primazia da observabilidade no empirismo construtivo de Van Fraassen - Alessio Gava 
edição grega do Scientific Image, de dezembro de 2004, van Fraassen afirmou essa necessidade de forma inequívoca: "Para explicar minha visão do que é a ciência, e especificamente qual é seu objetivo, eu preciso de uma viável distinção entre o que é observável e o que não é” (p. 1, tradução nossa).

Como foi dito no final da primeira seção e como o próprio van Fraassen parece reconhecer, sem uma linha divisória entre o observável e o inobservável o edifício filosófico construído por ele - assim como, provavelmente, qualquer construção empirista - desmoronaria. E se, conforme também disse o filósofo holandês, a cada século a filosofia se encontra na necessidade de reinterpretarse e o empirismo, como qualquer outra vertente, é forçado a 'renascer', como uma fênix, para não desaparecer, a ênfase no papel da observação parece todavia fazer parte das características hereditárias desse e nunca ter mudado. Dito de outra maneira, o empirismo construtivo pode até representar a (mais influente) versão contemporânea dessa antiga doutrina, mas a primazia que esse atribui à questão da observabilidade garante a continuidade com a atávica conduta empirista de manter-se 'dentro dos limites'.

\section{Referências bibliográficas}

ALSPECTOR-KELLY, Marc. Seeing the unobservable: van Fraassen and the limits of experience. Synthese, s.1., v. 140, n. 3, p. 331-353, jun. 2004.

AUNE, Bruce. An Empiricist Theory of Knowledge. BookSurge Publishing, 2009.

BAUMANN, Peter. Empiricism, stances, and the problem of voluntarism. Synthese, s.1., v. 178, p. 27-36, 2011.

BOYD, Richard. Scientific Realism. The Stanford Encyclopedia of Philosophy (Summer 2002 Edition). http://plato.stanford.edu/entries/scientific-realism. Último acesso em: 11 jun. 2007.

CARNAP, Rudolf. The Methodological Character of Theoretical Concepts. In: FEIGL, H.; SCRIVEN, M. (eds.), The Foundations of Science and the Concepts of Psychology and Psychoanalisis, Minnesota Studies in the Philosophy of Science, 1. Minneapolis: University of Minnesota Press, 1956, p. 38-76.

1974.

An introduction to the Philosophy of Science. New York: Basic Books,

CHAKRAVARTTY, Anjan. A Metaphysics for Scientific Realism. Knowing the Unobservable. New York: Cambridge University Press, 2007.

CHIBENI, Silvio Seno. Realismo Científico Empirista? Principia, Florianópolis, v. 1, n. 2, p. 255-269, 1997.

DICKEN, Paul. Constructive Empiricism. Epistemology and the Philosophy of Science. Palgrave Macmillan, 2010.

Empirismo e observação: uma perspectiva histórica sobre a primazia da observabilidade no empirismo construtivo de Van Fraassen - Alessio Gava 
ELLIS, Brian. What Science Aims to Do. In: CHURCHLAND, P. M.; HOOKER, C. A. (eds.), Images of Science. Essays on Realism and Empiricism, with a Reply form Bas C. van Fraassen. Chicago: The University of Chicago Press, 1985, p. 48-74.

FINE, Arthur. Unnatural Attitudes: Realist and Instrumentalist Attachments to Science. Mind, New Series, s.1., v. 95, n. 378, p. 149-179, abr. 1986.

FRAASSEN, Bas C. van. The Scientific Image. Oxford: Clarendon Press, 1980. - A Imagem Científica. Trad. de Luiz Henrique de Araújo Dutra. São Paulo: Editora UNESP / Discurso Editorial, 2007.

(2004). Preface to the Greek edition. http://www.princeton.edu/ fraassen/Sci-Img/ Sci_ImagePrefaceGreek.pdf. Último acesso em: 11 jun. 2007. . The Empirical Stance. New Haven: Yale University Press, 2002.

. The day of the dolphins. Puzzling over epistemic partnership. In: IRVINE, A.; PEACOCK, K. (eds.), Mistakes of Reason: Essays in Honour of John Woods. Toronto: University of Toronto Press, 2005, p. 111-133.

Press, 2008.

Scientific Representation: Paradoxes of Perspective. Oxford: Clarendon

FRANK, Philipp. Modern science and its philosophy. Cambridge: Harvard University Press, 1950.

HEMPEL Carl G. La formazione dei concetti e delle teorie nella scienza empirica. Trad. de Alberto Pasquinelli. Milano: Feltrinelli Editore, 1976.

LADYMAN, James. The Epistemology of Constructive Empiricism. In: MONTON, B. (ed.), Images of Empiricism. Essays on Science and Stances, with a Reply form Bas C. van Fraassen. Oxford: Clarendon Press, 2007b, p. 4661.

LUNTLEY, Michael. Verification, Perception, and Theoretical Entities. The Philosophical Quarterly, s.1., v. 32, n. 128, Special Issue: Scientifc realism, p. 245-261, jul. 1982.

MAXWELL, Grover. The ontological status of theoretical entities. Minnesota Studies in the Philosophy of Science, 3, Minneapolis: University of Minnesota Press, 1962, p. 3-27.

McMULLIN, Ernan. Van Fraassen's Unappreciated Realism. Philosophy of Science, s.1., n.70, p. 455-478, jul. 2003.

MENUGE, Angus. The Scope of Observation. The Philosophical Quarterly, s.1., v. 45, n. 178, p. 60-69, jun. 1995.

MONTON, Bradley (ed.), Images of Empiricism. Essays on Science and Stances, with a Reply form Bas C. van Fraassen. Oxford: Clarendon Press, 2007. 
MOSTERÍN, Jesus (1998). Technology-mediated observation. http://scholar.lib.vt.edu/ejournals/SPT/ v4_n2pdf/MOSTERIN.PDF. Último acesso em: 03 set. 2010.

NAGEL, Jennifer. The Empiricist Conception of Experience. Philosophy, s.1., v. 75, n. 3, p. 345-376, 2000.

. Empiricism. In: SARKAR, S.; PFEIFER, J. (eds.), The Philosophy of Science: An Encyclopedia. New York: Taylor \& Francis Group, 2006, p. 235243.

PESSOA JÚNIOR, Osvaldo. O canto do cisne da visão ortodoxa da filosofia da ciência. Scientiae Studia, São Paulo, v. 2, n. 2, p. 259-263, 2004.

PUTNAM, Hilary. What theories are not. In: Putnam's, Mathematics, Matter and Method, Philosophical Papers, v. 1. Cambridge: Cambridge University Press, 1962, p. 215-227.

SALMON, Wesley C. The Spirit of Logical Empiricism: Carl G. Hempel's Role in Twentieth-Century Philosophy of Science. Philosophy of Science, s.1., v. 66, n. 3, p. 333-350, set. 1999.

SANKEY, Howard. Scientific realism: an elaboration and a defence. Theoria, s.1., n. 98, p. 35-54, 2001.

SELLARS, Roy Wood. Causation and Perception. The Philosophical Review, s.1., v. 53, n. 6, p. 534-556, nov. 1944.

SHAPERE, Dudley. Observation. In: SARKAR, S.; PFEIFER, J. (eds.), The Philosophy of Science: An Encyclopedia. New York: Taylor \& Francis Group, 2006, p. 523-530.

SICHA, Jeffrey F. Reviewed Work: Images of Science. Essays on Realism and Empiricism, with a Reply form Bas C. van Fraassen by P. M. Churchland; C. A. Hooker. Noûs, s.1., v. 26, n. 4, p. 519-525, dez. 1992.

SOBER, Elliott. Empiricism. In S. Psillos and M. Curd (eds.), The Routledge Companion to the Philosophy of Science. New York: Routledge, 2008, p. 129138.

STEUP, Matthias. Empiricism, metaphysics, and voluntarism. Synthese, s.1., v. 178, p. 19-26, 2011.

VÁZQUEZ MONTALBÁN, Manuel. O labirinto grego. São Paulo: Companhia das Letras, 1992.

ZILLES, Urbano. Teoria do Conhecimento. Porto Alegre: EDIPUCRS, 2006 ( $5^{\mathrm{a}}$ ed.).

Empirismo e observação: uma perspectiva histórica sobre a primazia da observabilidade no empirismo construtivo de Van Fraassen - Alessio Gava 